\title{
Journal of Sport Coaching and Physical Education
}

\section{KONSERVASI BUDAYA BERPRESTASI MELALUI OLAHRAGA PETANQUE PADA SISWA SEKOLAH DASAR SE KABUPATEN PURBALINGGA}

\author{
${ }^{\bowtie}$ Rivan Saghita Pratama, ${ }^{\otimes}$ Taufiq Hidayah, ${ }^{\bowtie}$ Sri Haryono
}

Jurusan Pendidikan Kepelatihan Olahraga, Fakultas Ilmu Keolahragaan, Universitas Negeri Semarang, Indonesia

\section{Info Artikel}

Sejarah Artikel:

Diterima Juli 2018

Disetujui Juli 2018

Dipublikasikan

Agustus 2018

Keywords:

Konservasi, Budaya

Berprestasi, Olahraga

Petanque

\begin{abstract}
Abstrak
Kegiatan pengabdian ini dilaksanakan pada tanggal 14 - 15 April 2018. Pengabdian ini di ikuti oleh 30 dan 40 guru sekolah dasar Se Kabupaten Purbalingga yang diwadahi pada forum Kelompok Kerja Guru (KKG). Kegiatan pengabdian ini didukung oleh Dinas Pendidikan dan Kebudayaan Kabupaten Purbalingga dengan dikeluarkannya surat keterangan melaksanakan kegiatan dengan nomor surat 071/0789/2018. Metode pelaksanaan pengabdian kepada masyarakat ini berbentuk workshop untuk para guru dan siswa sekolah dasar se kabupaten purbalingga. Metode yang disajikan berbentuk ceramah, diskusi, dan eksperimen. Hasil yang dicapai ialah guru dan siswa secara sadar berkomitmen untuk menjaga, melindungi, dan melestarikan budaya berprestasi melalui olahraga petanque. Guru dan siswa sekolah dasar se kabupaten purbalingga akan menggiatkan olahraga petanque dan siap berpartisipasi dalam setiap kejuaraan yang diselenggarkan. Perwakilan siswa sekolah dasar kabupaten purbalingga siap mengikuti seleksi Eksebisi POPNAS cabang olahraga petanque yang akan diselenggarakan di Provinsi Papua pada tahun 2019. Dinas Pendidikan dan Kebudayaan Kabupaten Purbalingga melalui surat keterangan resminya menuliskan permohonan agar di tahun berikutnya agar dapat dilaksanakan kegiatan pengabdian kepada masyarakat ini dengan ruang lingkup kepersetaan yang lebih luas.
\end{abstract}

\begin{abstract}
This community service is held on April $14-15,2018$. This community service is followed by 30 students and 40 teachers in Kabupaten Purbalingga, that are accommodated in the Kelompok Kerja Guru (KKG) forum. This dedication activity is supported by Dinas Pendidikan dan Kebudayaan Kabupaten Purbalingga with the issuance of certificate of executing activity with letter number 071/0789/2018.

This method of community service is the form of workshops for teachers and elementary school students in Kabupaten Purbalingga. The method presented in the form oflectures, discussions, and experiments. The results achieved are teachers and students consciously committed to safeguarding, protecting, and preserving a culture of achievement through petanque sports. Teacher and students in Kabupaten Purbalingga will intensify the petanque sport and ready to participate in every championship held. Representatives of student ready to follow the selection POPNAS exhibition petanque sports branch that will be held in the province of Papua in 2019. Dinas Pendidikan dan Kebudayaan Kabupaten Purbalingga through official certificate to write a request for the next year in order to be implemented activities of dedication to this community with space wider scope of participant.
\end{abstract}

(C) 2018 Universitas Negeri Semarang ISSN 2548-4885

Gedung F1 Lantai 3 FIK UNNES

Kampus Sekaran, Gunungpati, Semarang, 50229

E-mail: jscpe.pklo@unnes.ac.id 


\section{PENDAHULUAN}

\begin{abstract}
Universitas Negeri Semarang adalah salah satu lembaga perguruan tinggi yang mempunyai tujuan mewujudkan kebudayaan yang unggul dalam pendidikan, melalui upaya pelestarian dan pengembangan nilai, pengetahuan, dan keyakinan berwawasan konservsi, Hal ini sesuai dengan visi UNNES yang tertera pada pasal 26 Peraturan Menteri Riset, Teknologi, dan Perguruan Tinggi Republik Indonesia nomor 49 tahun 2016 Visi Unnes adalah menjadi universitas yang berwawasan konservasi dan bereputasi internasional. Pendeklarasian UNNES sebagai universitas negeri semarang sebagai universitas konservasi pada tanggal 12 Maret 2010 oleh Menteri Pendidikan dan Kebudayaan yaitu Prof. Dr. Ir. KH. Mohammad Nuh, DEA.
\end{abstract}

Universitas konservasi ialah universitas yang dalam pelaksanaan pendidikan, penelitian, dan pengabdian masyarakat memiliki konsep yang mengacu pada prinsip-prinsip konservasi (perlindungan, pengawetan, dan pemafaatan secara lestari) baik konservasi terhadap sumber daya alam, lingkungan, seni dan budaya. Konservasi budaya memiliki tujuan untuk menjaga, melestarikan dan mengembangkan budaya untuk menguatkan jadi diri bangsa, sedangkan makna dari kata budaya menurut kamus besar bahasa Indonesia ialah sesuatu yang menjadi kebiasaan yang sudah sukar diubah. Kebiasan ini harus kita arahkan dalam hal positif, agar dapat berimbas pada kebermanfaatan lingkungan sekitar.

Olahraga mempunyai peranan penting dalam upaya meningkatkan kualitas sumber daya manusia. Olahraga membentuk manusia sehat dan memiliki kesegaran jasmani yang baik. Kesegaran jasmani dan kondisi fisik yang baik, dapat meningkatkan produktivitas dan prestasi kerja. Tujuan yang akan dicapai seseorang untuk melakukan kegiatan olahraga berbeda-beda, banyak jenis olahraga yang dapat dijadikan pilihan dalam kegiatan olahraganya, pemilihan olahraga tersebut tergantung pada minat masing-masing individu. Pembinaan dan pengembangan dilaksanakan melalui tahap pengenalan olahraga, pemantauan, pemanduan, serta pengembangan bakat dan prestasi. Olahraga prestasi sendiri dilaksanakan melalui proses pembinaan dan pengembangan secara terencana, berjenjang, dan berkelanjutan dengan dukungan ilmu pengetahuan dan teknologi keolahragaan guna mencapai prestasi baik tingkat daerah, nasional maupun internasional.

Budaya berprestasi dapat dimulai dari bangku sekolah dasar, budaya ini bisa menjadi motor penggerak siswa untuk berlomba berbuat yang terbaik dan menjadi yang terbaik, salah satu tujuan dari budaya prestasi di sekolah ialah mencegah siswa untuk melakukan hal yang bersifat negatif dari penggunaan obat-obatan terlarang sampai ke perbuatan kriminal lainnya. Budaya prestasi ini dapat dilakukan dengan memberikan suatu permainan, dimana bermain ialah dunia anak yang sesungguhnya. Aktivitas bermain ini dapat berpengaruh terhadap terbentuknya karakteristik anak.

Karakter merupakan perilaku yang ditunjukan oleh seseorang dalam kehidupan sehari-hari yang mempunyai kecenderungan kearah positif maupun negative. Dalam pendidikan tentu saja karakter positif yang ingin ditanamkan dalam diri peserta didik. Suharjana dalam 
Darmiyati Zuchdi (2011:28) yang dimaksud karakter adalah sebuah cara berfikir, bersikap, dan bertindak yang menjadi ciri khas seseorang yang menjadi kebiasaan yang ditampilkan dalam kehidupan bermasyarakat, kemudian suyatna dalam Darmiyati Zuchdi (2011:15) menyatakan bahwa karakter diartikan sebagai tersusun atas ciri-ciri yang memandu seseorang melakukan halhal yang benar atau mengerjakan hal-hal yang tidak benar.

Olahraga petanque adalah olahraga yang berasal dari Prancis. Olahraga petanque tergolong dalam cabang olahraga permainan yang didalamnya memerlukan tingkat akurasi dan konsentrasi yang baik. Olahraga ini menunjukan perkembangan yang sangat pesat, dilihat dari pertama kali olahraga ini masuk ke Indonesia di tahun 2011 dalam perhelatan Sea Games saat Indonesia menjadi tuan rumah. Olahraga petanque mempunyai 11 nomor diantaranya ialah nomor single man, single woman, double man, double women, double mix, triple man, triple woman, triple mix (one man and two women), triple mix (one women and two man), shooting man dan shooting women. Olahraga ini tidak hanya dipertandingkan dalam perhelatan sea games, akan tetapi olahraga ini juga dipertandingkan dalam Exebhisi Pomnas di Aceh 2015, Asean University Games di Singapura 2016, dan Eksebisi PON 2016 di Jawa Barat.

Hasil observasi penulis dilapangan mengenai aktivitas siswa disekolah diluar jam pelajaran, masih banyak siswa sekolah dasar yang pada jam istirahat menyibukan diri dengan bermain gadge, membeli makanan dan minuman yang kurang higienis, bercengkrama dengan teman sebaya didalam kelas, dan mengerjakan pekerjaan rumah (PR) di sekolah. Aktivitas seperti ini menunjukan bahwa siswa sangat minim untuk melakukan aktivitas geraknya, hal ini dapat menimbulkan beberapa kemungkinan diantaranya ialah obesitas, atrofi otot, kurangnya pembendaharaan pada gerak anak, serta perlambatan perkembangan dan pertumbuhan anak.

Berdasarkan uraian pada analisis situasi, dapat diidentifikasi adanya suatu permasalahan bahwa kurangnya pemahaman tentang konservasi budaya dalam hal pemeliharaan prestasi dan minimnya aktifitas gerak anak yang berdampak pada terjadinya obesitas pada anak, atrofi otot atau pengecilan otot yang dikarenakan minimnya gerak pada anak, kurangnya pembendaharaan gerak pada anak, serta perlambatan perkembangan dan pertumbuhan anak.

Olahraga petanque sebagai solusi dalam meningkatkan aktivitas gerak pada anak, sarana dan prasarana yang terjangkau membuat olahraga ini menjadi pilihan utama dalam mengatasi persoalan siswa yang malas untuk bergerak.

Sehubungan dengan hal tersebut maka perlu adanya penyuluhan tentang "Konservasi Budaya Berprestasi Melalui Olahraga Petanque Pada Siswa Sekolah Dasar Se Kabupaten Purbalingga".

\section{METODE}

Metode pelaksanaan pengabdian masyarakat yang berbentuk workshop untuk para guru dan mini turnamen olahraga petanque untuk para siswa sekolah dasar se kabupaten purbalingga. Metode yang disajikan dalam bentuk ceramah, diskusi dan ekperimen, serta mempraktekan langsung semua jenis gerakan dalam olahraga petanque.

\section{HASIL DAN PEMBAHASAN}


Kegiatan pengabdian ini dilaksanakan pada tanggal $14-15$ April 2018. Pengabdian ini di ikuti oleh 30 siswa sekolah dasar se Kabupaten Purbalingga dan 40 guru sekolah dasar Se Kabupaten Purbalingga yang diwadahi pada forum Kelompok Kerja Guru (KKG) se Kabupaten Purbalingga. Kegiatan pengabdian ini didukung oleh Dinas Pendidikan dan Kebudayaan Kabupaten Purbalingga dengan dikeluarkannya surat keterangan melaksanakan kegiatan dengan nomor surat 071/0789/2018.

Sesuai dengan Peraturan Rektor Universitas Negeri Semarang Nomor 27 Tahun 2012 tentang tata kelola kampus berbasis konservasi pada pasal 10 ayat 2 yang berbunyi "Program pilar kaderisasi konservasi meliputi sosialisasi, pelatihan, pendidikan, dan pelaksanaan kegiatan kepada warga Unnes untuk menguatkan pemahaman, penghayatan, dan tindakan berbasis konservasi. Penerapan peraturan ini sudah tim pengabdi laksanakan dengan memberikan pemahaman kepada para mahasiswa yang turut serta membantu dalam kegiatan pengabdian ini. Tim pengabdi juga mengembangkan kaderisasi konservasi ini kepada para stakeholder yang mana Dinas Pendidikan Purbalingga termasuk salah satu pengguna lulusan dari Universitas Negeri Semarang untuk mengembangkan dan mengabdikan potensi setelah lulus dan tuntas dalam menyelesaikan studi di Universitas Negeri Semarang.

Dinas Pendidikan Kabupaten Purbalingga juga membawahi Sekolah Dasar se Kabupaten Purbalingga yang mana beberapa Sekolah Dasar yang ada di Kabupaten Purbalingga menjadi pengguna lulusan dari Universitas Negeri Semarang. Dinas Pendidikan Kabupaten Purbalingga menyambut baik dan meneruskan surat permohonan dari tim pengabdi kepada seluruh guru pendidikan jasmani, olahraga, dan rekreasi sekolah dasar se Kabupaten Purbalingga melalui forum Kelompok Kerja Guru (KKG) untuk mengikuti kegiatan pengabdian ini.

$$
\text { Nilai konservasi yang }
$$
disosialisasikan kepada KKG Penjasorkes dan siswa sekolah dasar ialah bagaimana cara menjaga dan melestarikan budaya berprestasi para guru dan siswa sekolah dasar se Kabupaten Purbalingga. Melestarikan budaya berprestasi yang dimaksud ialah seorang guru dan siswa harus mampu berlomba-lomba untuk berani berkompetisi dan menorehkan prestasi yang maksimal. Prestasi yang maksimal tersebut diharapkan ada guru dan siswa dari kabupaten purbalingga untuk turut serta membawa nama baik bangsa dan negara.

Olahraga petanque memang tergolong baru di Indonesia. Olahraga ini masuk ke Indonesia pada tahun 2011 yang mana bertepatan dengan perhelatan akbar pesta olahraga se Asia Tenggara. Olahraga ini masuk ke Jawa Tengah pada tahun 2016. Walaupun tergolong baru, olahraga ini sudah dipertandingkan dibeberapa perhelatan multieven dan single event baik tingkat nasional maupun internasional. Olahraga petanque dipertandingkan dalam multieven tingkat internasional ialah Sea Games dan Eksebisi pada Olimpiade Japan 2020. Multieven tingkat nasional meliputi PON 2016, POMNAS 2017, PORPROV Jawa Tengah 2018.

Melihat peluang prestasi yang dapat ditorehkan melalui olahraga petanque, tim pengabdi ingin mengobarkan semangat konservasi budaya berpretasi untuk guru dan siswa melalui olahraga petanque. Melalui pengabdian kepada masyarakat ini, tim pengabdi juga memberikan penyuluhan tentang pentingnya aktivitas gerak untuk anak. Menurut Awi Muhadi Wijaya (2009:67) masa kecil sering disebut 
sebagai saat ideal untuk mempelajari keterampilan motorik dengan alasan sebagai berikut: (1) Tubuh anak lebih lentur ketimbang tubuh orang dewasa sehingga anak lebih mudah menguasai keterampilan motorik. (2) Anak belum banyak memiliki keterampilan yang akan menguasai berbenturan dengan keterampilan baru dipelajarinya, sehingga anak akan mempelajari keterampilan baru dengan lebih mudah. (3). Secara keseluruhan anak lebih berani mencoba pada saat kecil ketimbang setelah besar. Oleh karena itu mereka berani mencoba sesuatu yang baru, sehingga menimbulkan motivai yang diperlukan untuk belajar. (4) Anak-anak menyukai pengulangan, sehingga mereka bersedia mengulangi tindakan hingga otot telatih untuk melakukannya secara efektif. (5) Anak memiliki waktu yang lebih banyak untuk mempelajari keterampilan motorik.

Guru dan siswa yang mengikuti kegiatan pengabdian ini berkomitmen untuk menjaga, melindungi, dan melestarikan budaya berprestasi melalui olahraga petanque. Guru dan siswa sekolah dasar se kabupaten purbalingga akan menggiatkan olahraga petanque dan siap berpartisipasi dalam setiap kejuaraan yang diselenggarkan. Perwakilan siswa sekolah dasar kabupaten purbalingga siap mengikuti seleksi Eksebisi POPNAS cabang olahraga petanque yang akan diselenggarakan di Provinsi Papua pada tahun 2019. Dinas Pendidikan dan Kebudayaan Kabupaten Purbalingga melalui surat keterangannya menuliskan permohonan agar di tahun berikutnya agar dapat dilaksanakan kegiatan pengabdian kepada masyarakat ini dengan ruang lingkup yang lebih luas.

simpulan

Dari hasil pengabdian ini dapat disimpulkan bahwa: Kegiatan pengabdian kepada masyarakat ini sangat diminati oleh guru dan siswa Sekolah Dasar se Kabupaten Purbalingga. Antusiasme guru dalam mengikuti pengabdian ini ditunjukan dengan jumlah guru dan siswa sekolah dasar yang terlibat ialah sejumlah 40 orang guru dan 30 orang siswa. Hasil pengamatan tim pengabdi di lapangan pasca kegiatan pengabdian ini, ada salah seorang guru yang masuk dalam tim Porprov Kabupaten Purbalingga atas nama Khomsiyati dari SDN 2 Penaruban. Kegiatan pengabdian ini memberikan wawasan nilai-nilai konservasi yang ada di Universitas Negeri Semarang yang dapat diterapkan pada guru dan siswa dalam rangka menjaga dan melestarikan budaya berprestasi melalui olahraga petanque.

\section{DAFTAR PUSTAKA}

Buick, A. R, Mulligan, H. F \& Smith, C. M. 2015. Implementation of physical activity for individuals with severe neurological disability. New Zealand Journal of Physiotherapy, Volume 43 Number 3: 73-114.

Darmiyati Zuchdi. 2011. Pendidikan Karakter dalam Perspektif Teori dan Praktik. Yogyakarta : UNY Press.

FOPI. 2012a. Teknik Dasar Bermain Petanque. Jakarta: PB. FOPI.

FOPI. 2012b. Aturan Petanque. Jakarta: PB. FOPI.

FOPI. 2012c. Aturan Shooting. Jakarta: PB. FOPI.

Gilles. 2015. The Winning Trajectory: Petanque Trainning and Technique. Perancis: Copymedia. 
Harsono. 1988. Coaching dan AspekAspek Psikologis Dalam Coaching. Jakarta: Derjendikti.

Ismail, A.S. (Ed). 2015. Materi Pelatihan Umpire Cabang Olahraga Petanque. Jakarta: FIK UNJ.

Laoruengthana, A, et all. 2009. The Epidemiology of Sports Injury during the 37th Thailand National Games 2008 in Phitsanulok. J Med Assoc Thai 2009; 92 (Suppl 6): S204-10

Peraturan Menteri Riset, Teknologi, dan Perguruan Tinggi Republik Indonesia nomor 49 tahun 2016.

Undang - Undang Republik Indonesia No. 3 Tahun 2005 Tentang Sistem Keolahragaan Nasional. Yogyakarta : Pustaka Yustisia. 